\title{
Response to letter to the editor for original manuscript, "Surgical management of complex multiloculated hydrocephalus in infants and children"
}

\author{
Syed Hassan Abbas Akbari ${ }^{1}$ - David Delmar Limbrick ${ }^{1}$
}

Received: 2 April 2015 / Accepted: 9 April 2015 /Published online: 22 April 2015

(C) Springer-Verlag Berlin Heidelberg 2015

\section{Dear Editor:}

We appreciate Mr. Paraskevopoulos's insightful commentary on our recent manuscript, "Surgical management of complex multiloculated hydrocephalus in infants and children" (Childs Nerv Syst 31:243-249, 2015). We could not agree more with the sentiment that new and creative solutions are needed to treat this challenging neurosurgical problem. While endoscopy was often paired with image guidance in the treatment of the patients in this study and previous studies [1], we have not yet routinely integrated intraoperative imaging into our treatment paradigm for multiloculated hydrocephalus. We applaud Mr. Paraskevopoulos [2] and others [3-7] for broadening our treatment options through the development of more advanced adjunctive surgical tools.

Syed Hassan Abbas Akbari

akbaris@wudosis.wustl.edu

Saint Louis School of Medicine, Washington University, St. Louis, MO, USA

\section{References}

1. Mangano FT, Limbrick DD, Leonard JR, Park TS, Smyth MD (2006) Simultaneous image-guided and endoscopic navigation without rigid cranial fixation: application in infants: technical case report. Neurosurgery 58, E377

2. Paraskevopoulos D, Biyani N, Constantini S, BeniAdani L (2011) Combined intraoperative magnetic resonance imaging and navigated neuroendoscopy in children with multicompartmental hydrocephalus and complex cysts: a feasibility study. J Neurosurg Pediatr 8:279288

3. Balmer B, Bernays RL, Kollias SS, Yonekawa Y (2002) Interventional MR-guided neuroendoscopy: a new therapeutic option for children. J Pediatr Surg 37:668-672

4. Kollias SS, Bernays RL (2001) Interactive magnetic resonance imaging-guided management of intracranial cystic lesions by using an open magnetic resonance imaging system. J Neurosurg 95: $15-23$

5. Rhoton AL Jr, Gomez MR (1972) Conversion of multilocular hydrocephalus to unilocular. Case report. J Neurosurg 36:348350

6. Zuccaro G, Ramos JG (2011) Multiloculated hydrocephalus. Childs Nerv Syst 27:1609-1619

7. Shah MN, Leonard JR, Inder G, Gao F, Geske M, Haydon DH (2012) Intraoperative magnetic resonance imaging to reduce the rate of early reoperation for lesion resection in pediatric neurosurgery. J Neurosurg Pediatr 9: $259-264$ 